\title{
ANALYSIS OF VARIATORS IN THE BRCA1 AND BRCA2 GENES BY NGS IN PATIENTS FROM CENTRAL BRAZIL WITH SUSPECTED HBOC SYNDROME: A NEW PATHOGENIC VARIANT IDENTIFIED
}

Rebeca Mota Goveia' ${ }^{1}$ Paula Francinete Faustino da Silva' ${ }^{1}$ Thais Bomfim Teixeira², Ruffo de Freitas Júnior², Elisângela de Paula Silveira Lacerda ${ }^{1}$

'Laboratório de Genética Molecular d Citogenética, Universidade Federal de Goiás - Goiânia (GO), Brazil.

${ }^{2}$ Centro Avançado de Diagnóstico da Mama, Hospital das Clínicas da UFG - Goiânia (GO), Brazil.

About $10-15 \%$ of breast cancer cases are due to deleterious germ changes, more than half of which are located in the BRCA1 or BRCA2 genes. The screening of variants in these genes for patients at risk brings benefits for better clinical management of the patient as well as for the prevention of disease recurrences both in the proband and in their relatives. The profile of genetic variants is little known to the Brazilian population and, to date, there are no published data for the population of the central region of the country. This study aimed to analyze the profile of pathogenic variants (VP) and of uncertain significance (VUS) in the BRCA1 and BRCA2 genes in this population. We selected 102 patients seen at Hospital das Clínicas, Universidade Federal de Goiás, with clinical diagnosis of invasive ductal carcinoma that met the criteria of the National Comprehensive Cancer Networking 2016/2 for hereditary breast and ovarian cancer syndrome. A collection of $4 \mathrm{~mL}$ of peripheral blood was carried out and submitted to subsequent extraction of genomic DNA, carried out using the PureLink kit (Invitrogen). The genes in question had all their exon-intron regions sequenced using the MiSeq device (Illumina) and the raw data were evaluated using the Sophia DDM software. The risk of in silico pathogenicity of the VUS was analyzed by the software POLYPHEN2, MutationTaster, SIFT, ESP5400, G1000, GnomAD. Of the total of 102 patients evaluated in this study, $22(21.56 \%)$ had PV or VUS in the BRCA1 or BRCA2 genes. Of these, 16 patients $(72.81 \%)$ had pathogenic variants, eight with PV in BRCA1 (c.5266dupC (2), c.3331_3334delCAAC, c.211A>G, c.3228_3229delAG, c.3700_3704delGTAAA, c.4484G>T and c.5305_5306ins20) and eight with PV in BRCA2 (c.156_157insAlu, c.4829_4830delTG, c.8488-1G>A, c.6405_6409delCTTAA (3), c.517-1G>A, c.2808_2811delACAA). A total of 7 patients (31.8\%) presented VUS in these genes, one in the BRCA1 gene $(c .179 \mathrm{~A}>\mathrm{G})$ and five in the BRCA2 gene (c.280C $>\mathrm{T}, \mathrm{c} .811 \mathrm{G}>\mathrm{A}, 1096 \mathrm{~T}>\mathrm{G}, 1441 \mathrm{~A}>\mathrm{G}$ and c. $5270 \mathrm{~A}>\mathrm{G}$ ) of which only the variant c. $1441 \mathrm{~A}>\mathrm{G}$ had low pathogenic potential in silico. A new PV still not described in the literature was also identified, variant c.5305_5306ins20 in the BRCA1 gene. These data suggest that all patients at risk in this population should be evaluated for PV or VUS in the BRCA1 and BRCA2 genes since the presence of these variants can help in the patient's prognosis and disease prevention. 